\title{
The response of the host microcirculation to bacterial sepsis: does the pathogen matter?
}

\author{
Matthieu Legrand • Eva Klijn • Didier Payen • Can Ince
}

Received: 19 October 2009/Revised: 25 November 2009/Accepted: 21 December 2009 /Published online: 30 January 2010

(C) The Author(s) 2010. This article is published with open access at Springerlink.com

\begin{abstract}
Sepsis results from the interaction between a host and an invading pathogen. The microcirculatory dysfunction is now considered central in the development of the often deadly multiple organ dysfunction syndrome in septic shock patients. The microcirculatory flow shutdown and flow shunting leading to oxygen demand and supply mismatch at the cellular level and the local activation of inflammatory pathways resulting from the leukocyteendothelium interactions are both features of the sepsisinduced microcirculatory dysfunction. Although the host response through the inflammatory and immunologic response appears to be critical, there are also evidences that Gram-positive and Gram-negative bacteria can exert different effects at the microcirculatory level. In this review we discuss available data on the potential bacterial-specific microcirculatory alterations observed during sepsis.
\end{abstract}

Keywords Sepsis · Endothelium · Pathogen ·

Pathophysiology

\section{Introduction}

Septic shock occurs with an increasing incidence over years with a mortality rate remaining unacceptably high when

M. Legrand $(\bowtie) \cdot$ E. Klijn $\cdot$ C. Ince

Department of Intensive Care, Erasmus Medical Center,

Erasmus University of Rotterdam,

s Gravendijkwal 230,

3015 CE Rotterdam, The Netherlands

e-mail: m.legrand@libertysurf.fr

M. Legrand · D. Payen

Department of Anesthesiology and Critical Care,

Lariboisière Hospital, Assistance Publique-Hopitaux de Paris,

University of Paris 7 Denis Diderot,

2 rue Ambroise-Paré,

75475 Paris Cedex 10, France multiple organ dysfunction develops. Clinical research has brought attention to the association of microcirculatory dysfunction and sepsis. Back in 1922, Freedlander and Lenhart already observed the microcirculation from fingers of septic patients, using a standard microscope, and described "capillary stasis without evidence of cardiac decompensation" [1]. Subsequently, these authors and others used the term "endothelium intoxication" which was associated with "capillary stasis and increased permeability due to some products of traumatized or poorly metabolized tissue." Since that time, the pathophysiology of the microcirculatory dysfunction in septic shock has gained major insights. The sepsis is seen as a homogeneous entity resulting from a host inflammatory response to an invading pathogen [2], with an international definition, rarely referring to the nature of the infecting organism. However, the appreciation that the causative microorganisms in sepsis can have varying clinical consequences suggests that substantial differences in the pathophysiology of sepsis may be part of the syndrome. The epidemiology of sepsis is changing with an increasing proportion of cases due to Gram-positive bacteria which appear to yield a worse outcome compared to patients infected with Gramnegative microorganisms $[3,4]$. The purpose of this brief review is to discuss potential implications of the nature of the microorganism in the microcirculatory dysfunction observed in sepsis focusing on the differences observed between Gram-negative and Gram-positive bacteria.

\section{Microcirculatory disorders in sepsis: implications for disease}

The systemic and pulmonary microcirculations are targets of injury in the course of septic shock. There is overwhelming evidence that microcirculatory disorders occur in the course of septic shock with a decrease of density of 
perfused capillaries with sluggish or stop-flow perfusion patterns $[5,6]$. The functional consequence is that some local regions of tissue will be undersupplied with oxygen while others are being oversupplied due to microcirculatory blood flow shunting [7]. Oxygen diffusion distances will increase, and convective oxygen delivery to the cells will be impaired causing initially a mismatch between cell oxygen demand and supply. Tissue hypoxia can then trigger inflammatory pathways which potentially further cause tissue damage. These microcirculatory alterations have been associated with worse outcome and seem to be, at least partially, independent of the macrohemodynamic variables [8,9]. Red blood cells (RBCs) and platelets aggregation, endothelial cell swelling, arteriole vasoconstriction, endothelium injury, and increased microvascular permeability with interstitial edema are all factors proposed to be responsible for capillary flow shutdown [10]. Coagulation activation is another hallmark of sepsis with the inflammatory response activating tissue factor on endothelial cells and monocytes, intravascular thrombin generation, depletion of anticoagulant factors, and alterations of the fibrinolytic system [11]. Analysis of the Recombinant Human Activated Protein C Worldwide Evaluation in Severe Sepsis trial revealed that almost all patients with severe sepsis had stigma of coagulation activation. Markers of coagulation activation such as prothrombin time, level of D-dimer, or protein $\mathrm{C}$ were found to be profoundly abnormal [12]. This appeared to be slightly more pronounced in patients with Gram-negative sepsis and bacteremia although the greatest reduction in the mortality rate in patients treated with human drotrecogin alfa (activated), an antithrombotic-targeted therapy, was observed in Streptococcus pneumoniae-related sepsis [12].

Besides promoting leukocytes recruitment on the site of infection for bacterial clearance, endothelium activation will subsequently trigger local inflammation and contribute to tissue injury, including vascular injury [13]. Despite large amount of NO being produced by inducible nitric oxide synthase during sepsis, generation of superoxide by adhesive leukocytes can decrease endothelium-derived NO bioavailability and compromise microcirculatory blood flow by inducing vasoconstriction or lost of vasodilation [14].

\section{Nonspecific microcirculatory phenomena in bacterial sepsis}

Most of our current understanding of the molecular pathogenesis of sepsis-induced microvascular dysfunction has been derived from experimental animal models (Fig. 1). Downstream the bacterial signal, local and systemic inflammatory pathways activation are a hallmark of sepsis
[2]. The microvasculature will respond to inflammatory stimuli mainly through activation of the endothelium. On the front line is the expression of adhesion molecules which will enhance endothelial-leukocyte interaction [15]. Pselectin, which is preformed and stored in Weibel-Palade bodies in the endothelial cells, is exposed within minutes on the endothelial cell surface after proinflammatory stimulation while E-selectin, intercellular adhesion molecule-1, or vascular cellular adhesion molecule-1 are upregulated within hours by gene-transcription under regulation of transcription factors such as nuclear factor- $\mathrm{\beta} \beta(\mathrm{NF}-\mathrm{k} \beta)$ $[16,17]$.

Other NF- $k \beta$-regulated genes in endothelial cells include plasminogen activator inhibitor-1, cyclooxygenase-2, and inducible nitric oxide synthase [17], all involved in the microcirculatory blood flow regulation. Liaison of endothelial adhesion molecules to the neutrophil ligand Eselectin ligand-1 (ESL-1), P-selectin glycoprotein ligand-1, and CD44 will subsequently allow leukocyte adhesion and transmigration through the endothelial layer. Nonbacterial inflammatory stimulation such as tumor necrosis factor- $\alpha$ (TNF- $\alpha$ ) can disrupt the microvasculature, increase the vascular permeability [18], and promote leukocytes and bacterial recruitment [19]. Hidalgo et al. have recently shown how administration of TNF- $\alpha$ triggers interaction of leukocytes with circulating RBCs and platelets [20]. Interaction of the endothelial adhesion molecules Eselectin with its ligand ESL-1 on leukocytes initiated a second wave of activation after it upregulated the alphaM beta2 integrin on neutrophils, allowing interaction with RBCs and platelets. These interactions will in turn induce the formation of reactive oxygen species (ROS) by neutrophils and lead to impairment of capillary blood flow and vascular damage [21]. Decrease of endothelial cells' antioxidant defense mechanisms in sepsis can then further expose cells to ROS-induced damage [22]. The interactions of RBCs with leukocytes take place mainly in inflamed venules. The high shear stress may prevent leukocyteendothelium interaction in arterioles. The prevention of increased permeability of venules in platelet-depleted mice underlined the role of platelets in inflammation-induced vascular damage [23]. Angiotensin II is a another mediator which has been found to stimulate NF-K $\beta$ expression through induction of oxidative stress in endothelial cells, which in turn promote the expression of adhesion molecules [24]. Interestingly, Laschke et al. reported that stimulation of the endothelium with TNF- $\alpha$ does not necessarily translate into changes of microcirculatory blood flow. They found no difference in microhemodynamics after applying topically TNF- $\alpha$ on skinfold chamber of hamsters infected with Staphylococcus aureus [25]. Finally, it has been hypothesized that severe endothelial injury could impair bacterial clearance due to the inability of 
Fig. 1 Proposed Mechanisms of the role of microcirculatory alterations in sepsis-related multiple organ failure. Recognition of bacterial products by pattern-recognition receptor $(P R R)$ on immune and endothelial cells initiate host responses at the microcirculatory level leading to endothelial cells damage, leukocytes activation and adhesion, and production of reactive oxygen species $(R O S)$. Microcirculatory flow shutdown will follow due to microthrombi, interstitial edema, and alteration of vascular tone

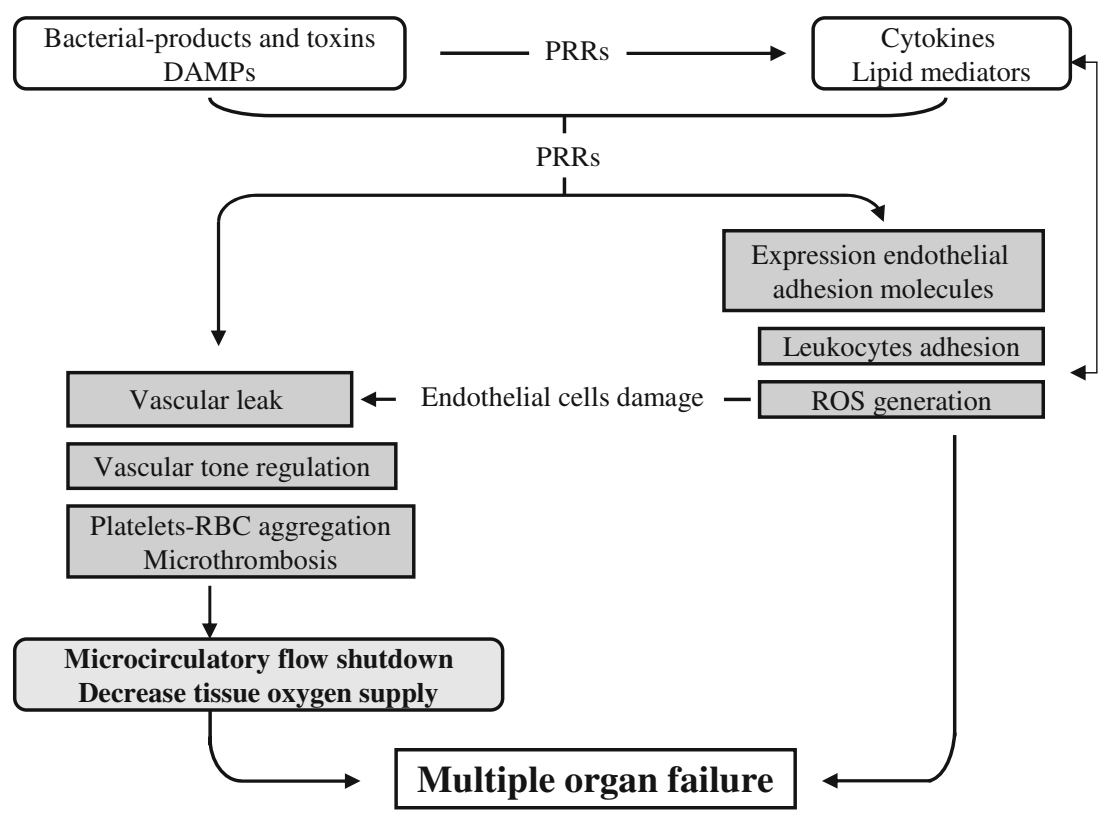

endothelial cells to undergo the active cytoskeletal rearrangements necessary to allow leukocyte transmigration [26]. We also have to bear in mind that the response of the endothelium to inflammatory stimuli may differ among different sites of the microvasculature and between organs. To conclude, microcirculatory perfusion abnormalities are often associated with sepsis and are thought to result from hemodynamic determinants, inflammation, and hostimmune response interactions. This ultimately leads to endothelial adhesion molecule expression with tissue recruitment of inflammatory cells and microcirculation perfusion alterations.

\section{The pathogen-specific microvascular alterations in bacterial sepsis: Gram-negative versus Gram-positive bacteria}

The outcome of a bacterial infection depends upon the molecular interactions between the invading microorganism and the human host. Although the mediators of inflammation appear to be central in the development of organ dysfunction, it is now appreciated that pathogens and pathogen-derived products from Gram-negative and Gram-positive bacteria called pathogen-associated molecular patterns (PAMPs) can activate different specific inflammatory pathways leading to microvascular injury (Table 1). Endotoxin is a lipopolysaccharide (LPS) from which most of the toxicity resides in the lipid $\mathrm{A}$ in the innermost core region. Even extremely debated, the presence of endotoxemia is thought to be a major component of the pathophysiology of Gram-negative bacterial sepsis and seems to correlate with severity of the disease [27]. Recently, the use of polymyxin B-immobilized hemoperfusion, to remove circulating endotoxin by adsorption, has been reported to improve hemodynamic variables during the course of abdominal sepsis [28]. Such a concept of circulating LPS as a risk factor fits, of course, well with Gram-negative infection but can also fit with Gram-positive infection. In this particular situation as in many other severe acute inflammations, LPS alone or Gram-negative bacteria may cross the tissue-vascular barrier, especially in the gut. Although LPS induces microcirculatory alterations, other bacterial factors can be involved in the leukocyte-endothelium interaction in the course of Gram-negative bacterial sepsis. This is illustrated by the study of Moreland et al. who found that intact Escherichia coli bacteria elicited much more PMN migration than purified E. coli LPS at corresponding LPS concentrations [19].

Endotoxemia is not a feature of Gram-positive bacterial sepsis. Indeed, the plasma membrane of gram-positive bacteria is surrounded by a thick layer of peptidoglycan, which embeds molecules of lipoteichoic acid (LTA). Yipp et al., using intravital microscopy to visualize muscle microvasculature in mice, have provided evidence that pathogen-derived products can exert different microvascular effects [29]. While local administration of LPS from $E$. coli induced leukocyte rolling, adhesion, and migration in postcapillary venules with increased expression of endothelial adhesion molecules, administration of LTA from $S$. aureus, had a minor effect on leukocyte-endothelial interaction or expression of these adhesion molecules. On the other hand, systemic injection of live $S$. aureus induced responses similar to LPS, probably partially mediated by peptidoglycan [30]. In the same line, Klintman et al. examined the liver microvascular effects of staphylococcal 


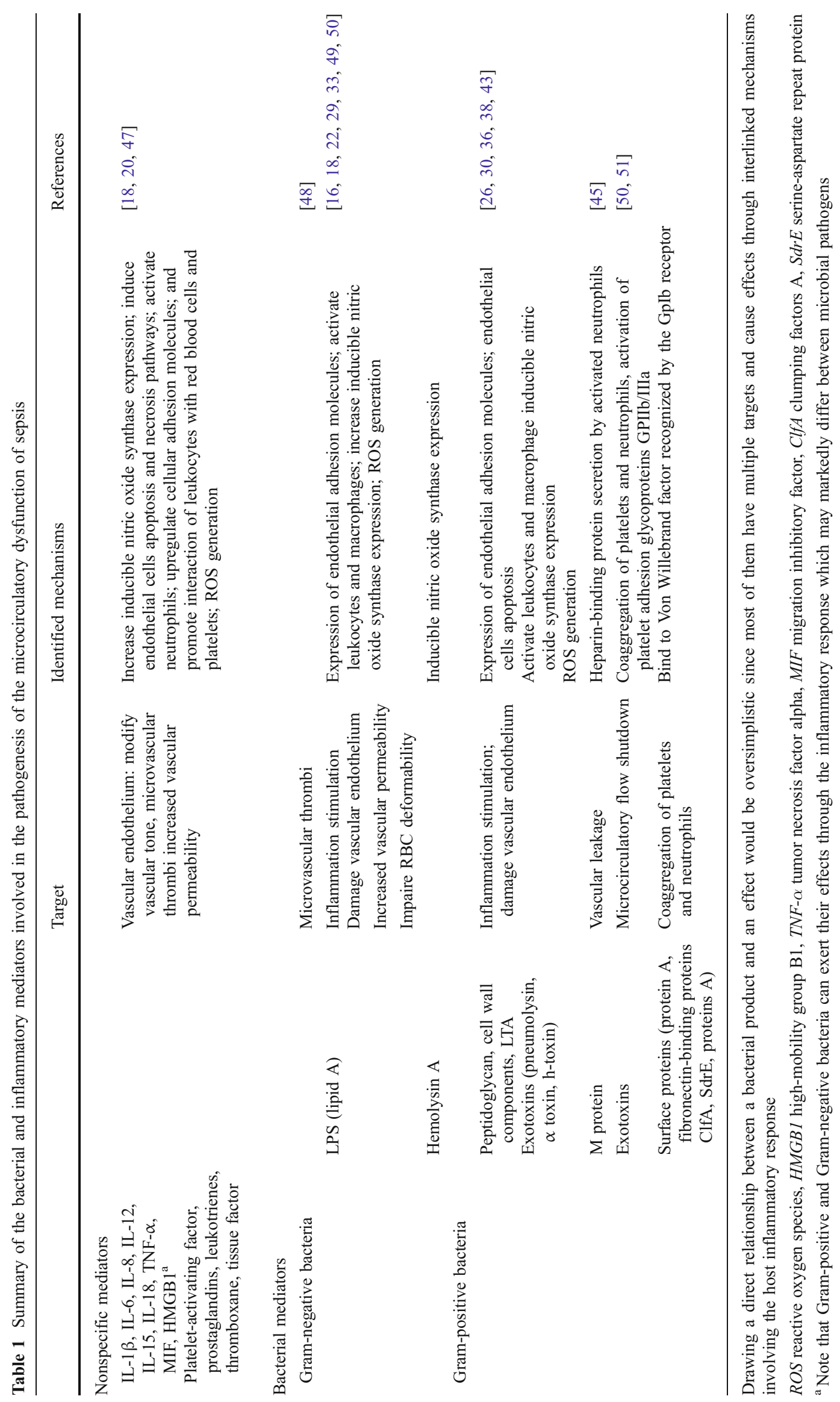


enterotoxin A and LPS in mice. They found that enterotoxin A-induced liver injury was FasL-mediated but was independent of leukocyte recruitment while LPS provoked a TNF- $\alpha$-dependent liver injury and enhanced leukocyte adhesion in the postsinusoidal venules [31].

These observations may arise from difference in expression of the Toll-like receptors (TLRs). TLRs have been identified as receptors able to recognize molecular structures of microorganisms termed PAMPs [32]. PAMPs include double-stranded RNA from bacteria products (LPS and LTA, respectively) and flagellin, a component of motile microorganisms. After binding to their ligands, TLRs activate transcription factors (namely intranuclear NF- $\kappa \beta$, activator protein-1, and interferon response factor-3) which result in the transcription of many proinflammatory genes, including inducible nitric oxide synthase, TNF- $\alpha$, and of interferon- $\beta$. TLR2, involved in the recognition of LTA, is not expressed on the endothelium, in contrast with the TLR4, which is involved in the recognition of LPS and found highly expressed on endothelial cells [33]. Activation of TLR2 or TLR4 can then result in different cytokine and chemokine gene transcription. This is coherent with some observations that patients with Gram-negative sepsis can have higher levels of the cytokine TNF- $\alpha$ and interleukin (IL)- 6 than Gram-positive patients do [34]. Finally, TLR5 has been identified as the specific receptor for the bacterial structural protein flagellin which is expressed on intestinal microvascular endothelial cells with a role in the intestinal innate immune response [35]. The pattern of this inflammatory response has been proposed to be informative of the nature of the pathogen involved.

The pathogenicity of microorganisms can also depend upon different membrane molecules expressions which determine their ability to interact with the endothelium. For instance, neutrophil migration in response to $S$. pneumoniae and $S$. aureus requires endothelial cell expression of CD18, whereas E. coli-induced migration seems independent of CD18 [19]. On the other hand, the pattern recognition molecule CD14 seems to be to LPS and of the Gram-positive bacterial components peptidoglycan and LTA. The ability of Neisseria meningitidis to cross the blood-brain barrier leading has been found to depend upon signals triggered by their type IV pili. Coureuil et al. found that after adhering and dividing onto brain endothelial cells, the bacteria will spread on the surface of the cells and mimic the signal of adherens junction's cell-cell formation which will disorganize the intercellular junctions and allow meningeal invasion [36].

Gram-positive bacteria can also exert endothelial toxicity through the release of various exotoxins. Pneumolysin is such an example common to all serotypes of $S$. pneumoniae. The endothelium is a major target of pore-forming bacterial exotoxins. Pneumolysin appeared to be required for the passage of pneumococci through the endothelial barrier by inducing endothelial cell apoptosis [37]. This makes pneumolysin an essential actor in the pathophysiology of bacterial meningitis allowing invasion of the cerebrospinal fluid from the blood compartment. Microvascular effects of pneumolysin have also been associated with pneumococcal-related acute lung injury. Intravascular administration of pneumolysin has been reported to result in an increase of pulmonary vascular resistance and permeability in a dose-dependent manner through plateletactivating factor-mediated release of thromboxane [38, 39]. S. aureus $\alpha$-toxin and E. coli hemolysin A are other examples of such toxin which can create an inner hydrophilic cavity in cell membrane leading to endothelial cell damage and subsequent vascular hyperpermeability [40]. For instance, $S$. aureus $\alpha$-toxin has been shown to increase vascular permeability by producing discontinuation of vascular junctional proteins (i.e., vascular-endothelialcadherin and occluding) [41]. Interestingly, although both $S$. aureus $\alpha$-toxin and E. coli hemolysin A can affect the myocardial circulation with increased coronary vascular resistance and loss in contractile function, the two exotoxins can exert different effects on myocardial perfusion. In a model of rat isolated hearts, Grandel et al. reported subendocardial perfusion impairment with hemolysin while $\alpha$-toxin rather impaired the epicardial microcirculatory flow [42]. Release of hemolysin A can then stimulate vasodilation through the stimulation of constitutive nitric oxide synthasedependant NO release [43].

Streptococcal toxic shock syndrome (STSS) arises from invasive Streptococcus pyogenes infections and is associated with a massive vascular leakage. Previous work has shown that secreted $S$. pyogenes streptolysin-O, a soluble extracellular toxin, plays an important role in the vascular dysfunction of STSS by inducing coaggregation of platelets and neutrophils mediated by platelet P-selectin [44]. Then, $\mathrm{M}$ protein contributes to the vascular leakage in STSS in activating neutrophils to secrete heparin-binding protein, a powerful inducer of increased vascular permeability [45]. Clostridium perfringens, a Gram-positive strict anaerobic bacteria, has also been reported to impair muscle microvascular blood flow. This effect is linked to the generation of intravascular platelet-leukocyte aggregates via activation of platelet adhesion glycoproteins GPIIb/IIIa and P-selectin by $\alpha$-toxin and h-toxin (also named perfringolysin $\mathrm{O}$ ) [26]. Finally, the staphylococcal superantigen-like protein 5 has been found to inhibit the leukocyte activation induced by chemokines and anaphylatoxins and can therefore prevent leukocyte recruitment on the site of infection. This illustrates the highly complex regulation of cellular response to the invading pathogen [46]. Therefore, there are evidences that pathogens can activate different pathways which will affect the microcirculation. The interaction of some pathogens or 
their products with the endothelium will be central in their pathogenicity (e.g., meningeal invasion and N. meningitidis and vascular leakage in STSS). On the other hand, although experimental data suggest specific signaling pathways, the microcirculatory alterations witnessed in sepsis appear to be mainly dependant on nonspecific host inflammatory and immune response. The paucity of clinical data on this issue appeals for well-designed clinical trials to better appreciate the respective role of the host response and pathogens in the microcirculatory alterations in sepsis.

\section{Conclusion}

Sepsis results from the interaction between a host and an invading pathogen associated with microcirculatory alterations. First, leukocytes and circulating inflammatory cells will be recruited on the site of infection by adhering to the endothelium and be activated for bacterial clearance with potential tissue damage as a consequence. Second, the systemic inflammatory and immune response to the pathogen will damage the endothelium in remote organs, increase the microcirculatory permeability, and induce production of reactive oxygen species which will compromise tissue oxygen supply. Some pathogens and their products can activate different pathways which are essential in their pathogenicity. However, the downstream host response in sepsis appears to be central in the development of microcirculatory dysfunction. Well-designed clinical trials are now required to determine whether targeting the microcirculatory compartment can prevent organ failure in sepsis.

Open Access This article is distributed under the terms of the Creative Commons Attribution Noncommercial License which permits any noncommercial use, distribution, and reproduction in any medium, provided the original author(s) and source are credited.

\section{References}

1. Freedlander SO, Lenhart CH (1922) Clinical observations on the capillary circulation. Arch Intern Med 29:12-32

2. Cohen J (2002) The immunopathogenesis of sepsis. Nature 420:885-891

3. Brun-Buisson C, Doyon F, Carlet J (1996) Bacteremia and severe sepsis in adults: a multicenter prospective survey in ICUs and wards of 24 hospitals. French bacteremia-sepsis study group. Am J Respir Crit Care Med 154:617-624

4. Martin GS, Mannino DM, Eaton S, Moss M (2003) The epidemiology of sepsis in the United States from 1979 through 2000. N Engl J Med 348:1546-1554

5. Boerma EC, van der Voort PH, Spronk PE, Ince C (2007) Relationship between sublingual and intestinal microcirculatory perfusion in patients with abdominal sepsis. Crit Care Med 35:1055-1060

6. De Backer D, Hollenberg S, Boerma C, Goedhart P, Buchele G, Ospina-Tascon G, Dobbe I, Ince C (2007) How to evaluate the microcirculation: report of a round table conference. Crit Care 11: R101

7. Ince C, Sinaasappel M (1999) Microcirculatory oxygenation and shunting in sepsis and shock. Crit Care Med 27:1369-1377

8. Dubin A, Pozo MO, Casabella CA, Pálizas F Jr, Murias G, Moseinco MC, Kanoore Edul VS, Pálizas F, Estenssoro E, Ince C (2009) Increasing arterial blood pressure with norepinephrine does not improve microcirculatory blood flow: a prospective study. Crit Care 13(3):R92

9. Trzeciak S, Dellinger RP, Parrillo JE, Guglielmi M, Bajaj J, Abate NL et al (2007) Early microcirculatory perfusion derangements in patients with severe sepsis and septic shock: relationship to hemodynamics, oxygen transport, and survival. Ann Emerg Med 49:88-98

10. Balestra GM, Legrand M, Ince C (2009) Microcirculation and mitochondria in sepsis: getting out of breath. Curr Opin Anaesthesiol 22:184-190

11. Opal SM, Garber GE, LaRosa SP, Maki DG, Freebairn RC, Kinasewitz GT, Dhainaut JF, Yan SB, Williams MD, Graham DE, Nelson DR, Levy H, Bernard GR (2003) Systemic host responses in severe sepsis analyzed by causative microorganism and treatment effects of drotrecogin alfa (activated). Clin Infect Dis 37(1):50-58

12. Dellinger RP (2003) Inflammation and coagulation: implications for the septic patient. Clin Infect Dis 36(10):1259-1265

13. Rittirsch D, Flierl MA, Ward PA (2008) Harmful molecular mechanisms in sepsis. Nat Rev Immunol 8:776-787

14. Price DT, Vita JA, Keaney JF Jr (2000) Redox control of vascular nitric oxide bioavailability. Antioxid Redox Signal 2:919-935

15. Zarbock A, Ley K (2009) Neutrophil adhesion and activation under flow. Microcirculation 16:31-42

16. Hippenstiel S, Suttorp N (2003) Interaction of pathogens with the endothelium. Thromb Haemost 89:18-24

17. De Martin R, Hoeth M, Hofer-Warbinek R, Schmid JA (2000) The transcription factor NF-kappa $\mathrm{B}$ and the regulation of vascular cell function. Arterioscler Thromb Vasc Biol 20:E83-E88

18. Henry CB, Duling BR (2000) TNF-alpha increases entry of macromolecules into luminal endothelial cell glycocalyx. Am J Physiol Heart Circ Physiol 279:H2815-H2823

19. Moreland JG, Bailey G, Nauseef WM, Weiss JP (2004) Organismspecific neutrophil-endothelial cell interactions in response to Escherichia coli, Streptococcus pneumoniae, and Staphylococcus aureus. J Immunol 172:426-432

20. Hidalgo A, Chang J, Jang JE, Peired AJ, Chiang EY, Frenette PS (2009) Heterotypic interactions enabled by polarized neutrophil microdomains mediate thromboinflammatory injury. Nat Med 15:384-391

21. Tyml K, Li F, Wilson JX (2008) Septic impairment of capillary blood flow requires nicotinamide adenine dinucleotide phosphate oxidase but not nitric oxide synthase and is rapidly reversed by ascorbate through an endothelial nitric oxide synthase-dependent mechanism. Crit Care Med 36:2355-2362

22. Huet O, Cherreau C, Nicco C, Dupic L, Conti M, Borderie D, Pene F, Vicaut E, Benhamou D, Mira JP, Duranteau J, Batteux F (2008) Pivotal role of glutathione depletion in plasma-induced endothelial oxidative stress during sepsis. Crit Care Med 36:2328-2334

23. Lister KJ, James WG, Hickey MJ (2007) Immune complexes mediate rapid alterations in microvascular permeability: roles for neutrophils, complement, and platelets. Microcirculation 14 (7):709-722

24. Alvarez A, Cerda-Nicolas M, Naim Abu Nabah Y, Mata M, Issekutz AC, Panes J, Lobb RR, Sanz MJ (2004) Direct evidence 
of leukocyte adhesion in arterioles by angiotensin II. Blood 104:402-408

25. Laschke MW, Kerdudou S, Herrmann M, Menger MD (2005) Intravital fluorescence microscopy: a novel tool for the study of the interaction of Staphylococcus aureus with the microvascular endothelium in vivo. J Infect Dis 191:435-443

26. Hickey MJ, Kwan RY, Awad MM, Kennedy CL, Young LF, Hall P, Cordner LM, Lyras D, Emmins JJ, Rood JI (2008) Molecular and cellular basis of microvascular perfusion deficits induced by Clostridium perfringens and Clostridium septicum. PLoS Pathog 4:e1000045

27. Opal SM, Cohen J (1999) Clinical Gram-positive sepsis: does it fundamentally differ from gram-negative bacterial sepsis? Crit Care Med 27:1608-1616

28. Cruz DN, Antonelli M, Fumagalli R, Foltran F, Brienza N, Donati A, Malcangi V, Petrini F, Volta G, Bobbio Pallavicini FM, Rottoli F, Giunta F, Ronco C (2009) Early use of polymyxin B hemoperfusion in abdominal septic shock: the EUPHAS randomized controlled trial. JAMA 301:2445-2452

29. Yipp BG, Andonegui G, Howlett CJ, Robbins SM, Hartung T, Ho M, Kubes P (2002) Profound differences in leukocyte-endothelial cell responses to lipopolysaccharide versus lipoteichoic acid. J Immunol 168:4650-4658

30. Buerke M, Sibelius U, Grandel U, Buerke U, Grimminger F, Seeger W, Meyer J, Darius H (2002) Staphylococcus aureus alpha toxin mediates polymorphonuclear leukocyte-induced vasocontraction and endothelial dysfunction. Shock 17:30-35

31. Klintman D, Li X, Sato T, Wang Y, Jeppsson B, Thorlacius H (2004) Staphylococcal enterotoxin A-induced hepatotoxicity is predominantly mediated by Fas ligand (CD95L). Ann Surg 240:1065-1072

32. Leaver SK, Finney SJ, Burke-Gaffney A, Evans TW (2007) Sepsis since the discovery of Toll-like receptors: disease concepts and therapeutic opportunities. Crit Care Med 35:1404-1410

33. Faure E, Equils O, Sieling PA, Thomas L, Zhang FX, Kirschning CJ, Polentarutti N, Muzio M, Arditi M (2000) Bacterial lipopolysaccharide activates NF-kappaB through toll-like receptor 4 (TLR-4) in cultured human dermal endothelial cells. Differential expression of TLR-4 and TLR-2 in endothelial cells. J Biol Chem 275:11058-11063

34. Fisher CJ Jr, Opal SM, Dhainaut JF, Stephens S, Zimmerman JL, Nightingale P, Harris SJ, Schein RM, Panacek EA, Vincent JL et al (1993) Influence of an anti-tumor necrosis factor monoclonal antibody on cytokine levels in patients with sepsis. The CB0006 sepsis syndrome study group. Crit Care Med 21:318-327

35. Maaser C, Heidemann J, von Eiff C, Lugering A, Spahn TW, Binion DG, Domschke W, Lugering N, Kucharzik T (2004) Human intestinal microvascular endothelial cells express Toll-like receptor 5: a binding partner for bacterial flagellin. J Immunol 172:5056-5062

36. Hirst RA, Kadioglu A, O'Callaghan C, Andrew PW (2004) The role of pneumolysin in pneumococcal pneumonia and meningitis. Clin Exp Immunol 138:195-201

37. Coureuil M, Mikaty G, Miller F, Lécuyer H, Bernard C, Bourdoulous S, Duménil G, Mège RM, Weksler BB, Romero IA, Couraud PO, Nassif X (2009) Meningococcal type IV pili recruit the polarity complex to cross the brain endothelium. Science 325 (5936):83-87

38. Garcia-Suarez Mdel M, Florez N, Astudillo A, Vazquez F, Villaverde R, Fabrizio K, Pirofski LA, Mendez FJ (2007) The role of pneumolysin in mediating lung damage in a lethal pneumococcal pneumonia murine model. Respir Res 8:3

39. Witzenrath M, Gutbier B, Owen JS, Schmeck B, Mitchell TJ, Mayer K, Thomas MJ, Ishii S, Rosseau S, Suttorp N, Schütte H (2007) Role of platelet-activating factor in pneumolysin-induced acute lung injury. Crit Care Med 35(7):1756-1762

40. Krull M, Dold C, Hippenstiel S, Rosseau S, Lohmeyer J, Suttorp N (1996) Escherichia coli hemolysin and Staphylococcus aureas alpha-toxin potently induce neutrophil adhesion to cultured human endothelial cells. J Immunol 157:4133-4140

41. Hocke AC, Temmesfeld-Wollbrueck B, Schmeck B, Berger K, Frisch EM, Witzenrath M, Brell B, Suttorp N, Hippenstiel S (2006) Perturbation of endothelial junction proteins by Staphylococcus aureus alpha-toxin: inhibition of endothelial gap formation by adrenomedullin. Histochem Cell Biol 126(3):305-316

42. Grandel U, Bennemann U, Buerke M, Hattar K, Seeger W, Grimminger F, Sibelius U (2009) Staphylococcus aureus alphatoxin and Escherichia coli hemolysin impair cardiac regional perfusion and contractile function by activating myocardial eicosanoid metabolism in isolated rat hearts. Crit Care Med 37 (6):2025-2032

43. Suttorp N, Fuhrmann M, Tannert-Otto S, Grimminger F, Bhadki S (1993) Pore-forming bacterial toxins potently induce release of nitric oxide in porcine endothelial cells. J Exp Med 178:337-341

44. Kahn F, Morgelin M, Shannon O, Norrby-Teglund A, Herwald H, Olin AI, Bjorck L (2008) Antibodies against a surface protein of Streptococcus pyogenes promote a pathological inflammatory response. PLoS Pathog 4:e1000149

45. Gautam N, Olofsson AM, Herwald H, Iversen LF, LundgrenAkerlund E, Hedqvist P, Arfors KE, Flodgaard H, Lindbom L (2001) Heparin-binding protein (HBP/CAP37): a missing link in neutrophil-evoked alteration of vascular permeability. Nat Med 7:1123-1127

46. Bestebroer J, van Kessel KP, Azouagh H, Walenkamp AM, Boer IG, Romijn RA, van Strijp JA, de Haas CJ (2009) Staphylococcal SSL5 inhibits leukocyte activation by chemokines and anaphylatoxins. Blood 113:328-337

47. Gao XP, Standiford TJ, Rahman A, Newstead M, Holland SM, Dinauer MC, Liu QH, Malik AB (2002) Role of NADPH oxidase in the mechanism of lung neutrophil sequestration and microvessel injury induced by Gram-negative sepsis: studies in p47phox-/- and gp91phox-/- mice. J Immunol 168:3974-3982

48. Melican K, Boekel J, Månsson LE, Sandoval RM, Tanner GA, Källskog O, Palm F, Molitoris BA, Richter-Dahlfors A (2008) Bacterial infection-mediated mucosal signalling induces local renal ischaemia as a defence against sepsis. Cell Microbiol 10:1987-1998

49. Poschl JM, Leray C, Ruef P, Cazenave JP, Linderkamp O (2003) Endotoxin binding to erythrocyte membrane and erythrocyte deformability in human sepsis and in vitro. Crit Care Med 31:924-928

50. O'Brien L, Kerrigan SW, Kaw G, Hogan M, Penades J, Litt D, Fitzgerald DJ, Foster TJ, Cox D (2002) Multiple mechanisms for the activation of human platelet aggregation by Staphylococcus aureus: roles for the clumping factors ClfA and ClfB, the serineaspartate repeat protein $\mathrm{SdrE}$ and protein $\mathrm{A}$. Mol Microbiol 44:1033-1044

51. Bryant AE, Bayer CR, Chen RY, Guth PH, Wallace RJ, Stevens DL (2005) Vascular dysfunction and ischemic destruction of tissue in Streptococcus pyogenes infection: the role of streptolysin Oinduced platelet/neutrophil complexes. J Infect Dis 192:1014-1022 